\title{
Synergistic inhibition of polyethylene glycol and potassium chloride in water-based drilling fluids
}

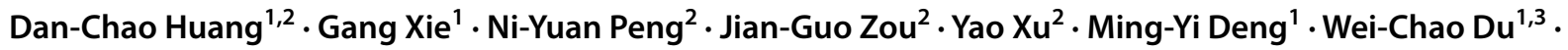 \\ Yu-Rong Xiao ${ }^{1} \cdot$ Jin-Jun Huang ${ }^{1} \cdot$ Ping-Ya Luo ${ }^{1}$
}

Received: 25 November 2019 / Accepted: 9 November 2020 / Published online: 15 February 2021

(c) The Author(s) 2021

\begin{abstract}
Mud shale hydration and swelling are major challenges in the development of water-based drilling fluids (WBDFs). In this work, the inhibition performance and inhibition mechanism of polyethylene glycol (PEG) and potassium chloride $(\mathrm{KCl})$ were investigated by hot rolling recovery tests, linear swell tests, Fourier transform infrared spectroscopy, X-ray diffraction, atomic absorption spectrophotometry and X-ray photoelectron spectroscopy. The experimental results show that the combination of PEG and $\mathrm{KCl}$ achieved higher recovery and lower linear swelling rate than those obtained by individual PEG or $\mathrm{KCl}$. Compared to the $d$-spacing of Na-montmorillonite (Na-Mt) with PEG or KCl, the $d$-spacing of Na-Mt with PEG+KCl was lower, which indicates that $\mathrm{KCl}$ and PEG have synergistic inhibition effect. This synergistic effect can replace sodium ions and water molecules from the interlayer space of Na-Mt and decrease the $d$-spacing of Na-Mt. Based on the above experimental results and analysis, a method for optimizing PEG and $\mathrm{KCl}$ concentrations was proposed and further verified by rheological and hot rolling recovery tests of WBDFs. Hence, the results of this work can provide valuable theoretical guidance for developing other synergistic inhibitors.
\end{abstract}

Keywords Clay hydration · Inhibitor $\cdot$ Synergistic inhibition $\cdot$ Polyethylene glycol $\cdot$ Water-based drilling fluids

\section{Introduction}

Shale oil and gas resources have been attracting a considerable amount of attention in recent years (Qian et al. 2020; $\mathrm{Li}$ et al. 2020). Severe wellbore instability frequently occurs during drilling of water-sensitive shale formations, which account for 75\% of the drilling formations (Bol et al. 1994; Dzialowski et al. 1993; Steiger and Leung 1992; Li et al.

Edited by Yan-Hua Sun

Gang Xie

201899010129@swpu.edu.cn

$\triangle$ Ping-Ya Luo

luopy@swpu.edu.cn

1 State Key Laboratory of Oil \& Gas Reservoir Geology and Exploitation, Southwest Petroleum University, Chengdu 610500, Sichuan, China

2 College of Chemistry and Chemical Engineering, Southwest Petroleum University, Chengdu 610500, Sichuan, China

3 College of Chemistry and Chemical Engineering, Xi' an Shiyou University, Xi' an 710056, Shanxi, China
2020). When water-sensitive shale comes into contact with water-based drilling fluids (WBDFs), hydration and swelling of clay minerals occur, which can generate wellbore instability (Cook et al. 1993; Mody and Hale 1993; van Oort 2003; Guo et al. 2006; Al-Bazali 2011). This results in several downhole complications, including wellbore collapse, wellbore shrinkage, pipe sticking and bit balling, which can increase both drilling times and costs (Khodja et al. 2010; Liu et al. 2006; Wang et al. 2009; Cai et al. 2008; Baohua et al. 2013; Li et al. 2015). In many cases, oil-based/synthetic-based drilling fluids are used to ensure swelling inhibition in water-sensitive formations (Li et al. 2016a, 2019). Despite their benefits, such as well inhibition ability, temperature resistance and lubricity, the oil-based drilling fluids lead to environmental pollution and high costs, limiting their application in the field. Therefore, WBDFs are the focus of much research, and the most important task in the research of WBDFs is to develop an excellent swelling inhibitor.

In the field of WBDFs, amine inhibitors have emerged as a research focus, but there are some environmental problems associated with this class of chemicals. However, polyols, as inhibitors for WBDFs, satisfy international environmental 
standards in terms of toxicity and biodegradability (Twynam et al. 1994). In addition, polyols have the advantages of water solubility, lubricity, thermal stability and compatibility with conventional treatment in the WBDFs (Bland et al. 1996; Bland 1992). In 1940, Cannon (1940) successfully tackled the shale swelling problem during drilling of a water-sensitive formation with 30\% ethylene glycol and propylene glycol in the WBDFs. A large number of field applications and laboratory studies have shown that polyols have an excellent inhibition performance in the presence of $\mathrm{KCl}$ (Bland 1992). Low-salinity glycol WBDFs have been developed for shale drilling in environmentally sensitive locations (Brady et al. 1998). KCl-PHPA-polyols were used to maintain borehole stability and reduce torque in the Sobhasan oilfield of India (Raza Khan et al. 2006). Moreover, polyol and potassium carbonate were applied as inhibitors to the Kanina oilfields of Albania (Isinak et al. 2005). In the deep exploratory wells of the Assam oilfield, polyol-KCl drilling fluids effectively inhibited clay swelling, improved wettability of drill pipe and reduced torque. The combination of polyethylene glycol (PEG) and $\mathrm{KCl}$ exhibits better inhibition performance than that provided by individual PEG or $\mathrm{KCl}$. The mechanism of synergistic inhibition is related to a complexation between PEG and $\mathrm{K}^{+}$, which can weaken the hydration of $\mathrm{K}^{+}$(Sartori et al. 1990; Tasaki et al. 1999). Boulet (2004) demonstrated that $\mathrm{PEG}+\mathrm{KCl}$ can decrease the layer spacing of Mt crystalline to $1.40 \mathrm{~nm}$, and PEG adopts a single-layer structure. However, the mechanism of synergistic inhibition caused by $\mathrm{PEG}+\mathrm{KCl}$ is still not well understood and needs to be theoretically explored. Moreover, no studies have yet proposed a general principle to optimize the concentrations of these two inhibitors for WBDFs.

In this study, the synergistic inhibition effect of PEG and $\mathrm{KCl}$ was investigated through linear swell tests and hot rolling recovery tests. After that, Fourier transform infrared spectroscopy (FTIR), X-ray diffraction (XRD), elemental analysis (EA), atomic absorption spectrophotometry (AAS), X-ray photoelectron spectroscopy (XPS) and scanning electron microscopy (SEM) were used to demonstrate and reveal the complex mechanism of this synergistic inhibition. Based on the proposed mechanism, a principle of optimizing concentrations of PEG and $\mathrm{KCl}$ in WBDF was put forward. Both the inhibition mechanism and optimization principle were verified against the results of drilling fluid tests in the laboratory.

\section{Experimental}

\subsection{Materials}

The chemical composition of Na-montmorillonite (Na-Mt) (obtained from the Nanocor Company) was as follows:
$71.30 \% \mathrm{SiO}_{2}, 13.22 \% \mathrm{Al}_{2} \mathrm{O}_{3}, 4.79 \% \mathrm{Na}_{2} \mathrm{O}, 7.10 \% \mathrm{MgO}$ and $3.59 \% \mathrm{Fe}_{2} \mathrm{O}_{3}$, which was determined with the $\mathrm{X}$-ray diffraction method. The cation exchange capacity (CEC) of Na-Mt was $113 \mathrm{meq} / 100 \mathrm{~g}$. Drill cuttings were purchased from the Center for Well Completion and Logging Laboratory and had $58.7 \%$ clay and $41.3 \%$ non-clay. Polyacrylamide (PAM) (anionic; mean molecular weight of $3 \times 10^{6}$ ), carboxymethyl cellulose (CMC), polyethylene glycol (PEG, mean molecular weight of 500), $\mathrm{Na}_{2} \mathrm{CO}_{3}$ and $\mathrm{KCl}$ were purchased from Chengdu Micxy Chemical Co., Ltd. Bentonite was purchased from Xinjiang Zhongfei Xiazi Street Bentonite Co., Ltd.

\subsection{Sample preparation}

The sample pretreatment process is as follows. Na-Mt was dried at $150{ }^{\circ} \mathrm{C}$ for $24 \mathrm{~h}$. Then, $1 \mathrm{~g}$ of dry Na-Mt was added to $25 \mathrm{~mL}$ of distilled water. After $3 \mathrm{~h}$ of stirring at $30^{\circ} \mathrm{C}$, the $\mathrm{Na}-\mathrm{Mt}$ dispersion was added to $25 \mathrm{~mL}$ of inhibitor solution of different concentrations. Then, the dispersion was stirred at $30{ }^{\circ} \mathrm{C}$ for $24 \mathrm{~h}$ and centrifuged at $5000 \mathrm{rpm}$ for $25 \mathrm{~min}$. The centrifugal sediment was added to $25 \mathrm{~mL}$ of distilled water and stirred with a glass rod. After that, the samples were centrifuged and washed three times by water.

In order to facilitate the description and comparison of the experimental results, two types of samples are defined: wet $\mathrm{Na}-\mathrm{Mt} /$ inhibitor samples and dry Na-Mt/inhibitor samples. The pre-treated samples are wet $\mathrm{Na}-\mathrm{Mt} /$ inhibitor samples. Dry Na-Mt/inhibitor samples were obtained through drying the wet sample at $150{ }^{\circ} \mathrm{C}$ for $24 \mathrm{~h}$ and complete grinding.

\subsection{Methods}

\subsubsection{Inhibition performance evaluation}

Hot rolling recovery tests are performed as follows. A total of $50 \pm 0.01 \mathrm{~g}$ drill cuttings were passed through a 10-mesh sieve and dried at $105 \pm 3{ }^{\circ} \mathrm{C}$ for $4 \mathrm{~h}$. The drill cuttings were added to high-temperature aging tanks with $350 \mathrm{~mL}$ of $1 \%$ inhibitor solution. The tanks were aged in a roller oven at $120{ }^{\circ} \mathrm{C}$ for $16 \mathrm{~h}$. After hot rolling, the drill cuttings were passed through a 40 -mesh sieves and dried at $105 \pm 3{ }^{\circ} \mathrm{C}$ for $4 \mathrm{~h}$. Cuttings were cooled to room temperature and weighed $(m)$. The first hot rolling recovery $\left(R_{1}\right)$ was the ratio of residual drill cuttings after first aging. The cuttings from the first recovery were aged a second and a third time. The first, second and third hot rolling recovery of the drill cuttings $\left(R_{1}, R_{2}, R_{3}\right)$ were calculated using Eq. (1):

$R_{i}=\frac{m_{i}}{50} \times 100 \%$ 
where $m_{i}$ is the recovery mass of cuttings $(i=1,2,3) ; R_{i}$ is the cutting recovery, $\%$.

Linear swell tests were performed as follows. A total of $10 \pm 0.01 \mathrm{~g}$ of drill cuttings were passed through a 100mesh sieve and dried at $105 \pm 3{ }^{\circ} \mathrm{C}$ for $4 \mathrm{~h}$. After that, the drill cuttings were added to test tubes and compressed at $4 \mathrm{MPa}$ for $5 \mathrm{~min}$. The pressure was then relieved, and the original height of the cutting column $(H)$ was measured with a Vernier caliper.

Then, the cutting column was installed in the linear dilatometer. Certain concentrations of inhibitor solution were added to the linear dilatometer until the solution is above the top of the cutting column. With the change of time, the changes in the height of the cutting column were recorded. At last, the linear swell ratio was calculated using Eq. (2):

$W_{t}=\frac{H_{t}}{H} \times 100 \%$

where $W_{t}$ is the percentage of linear swell ratio; $H$ is the original height of the cutting column in $\mathrm{mm}$; and $H_{t}$ is the height of the cutting column at time $t, \mathrm{~mm}$.

\subsubsection{Structure characterization and morphology observation}

Fourier transform infrared spectroscopy (FTIR) was used to investigate the organic adsorption on clay. FTIR was performed using a Nicolet 6700 FTIR spectrometer (Thermo Scientific Corporation, USA).

The layer spacing of Mt $\left(d_{001}\right)$ crystal plane is usually defined as $d$-spacing (Chaudhary et al. 2013; Lee et al. 2005). X-ray diffraction (XRD) can be used to study the $d$-spacing of Na-Mt. The XRD patterns of the samples were obtained with an X'Pert Pro MPD diffractometer (a $\mathrm{Cu} \mathrm{K} \alpha$ radiation source) at $2 \theta$ angles scanned from $3^{\circ}$ to $40^{\circ}$. The $d$-spacing of the samples were analyzed through Bragg's equation (Xie et al. 2017).

Ion adsorption can be investigated through elemental analysis, atomic absorption spectroscopy (AAS) and $\mathrm{X}$-ray photoelectron spectroscopy (XPS). In this study, the carbon content was measured using a Var10EL-III elemental analyzer (Germany). Dry Na-Mt samples, which were prepared in Sect. 2.2, were used to evaluate the content of potassium and sodium ions on a SHIMADZU AA-6300C atomic absorption spectrophotometer. XPS analysis of the compacted samples was assessed with an ESCALAB 250X-ray photoelectron spectrometer.

The morphology of wet Na-Mt samples, which were prepared in Sect. 2.2, was observed with environmental scanning electron microscope (SEM). SEM was performed with a Quanta 650F instrument.

\subsubsection{Inhibition performance evaluation of WBDF}

To evaluate the inhibition performance of WBDF with inhibitors, the following steps are required. (1) The preparation of the WBDF with inhibitors. The formulation of the basic WBDF is listed in Table 1 . The bentonite and $\mathrm{Na}_{2} \mathrm{CO}_{3}$ were added to $200 \mathrm{~mL}$ of freshwater and pre-hydrated at room temperature for $24 \mathrm{~h}$. Then, the other agents (as shown in Table 1) were slowly added to the system and stirred thoroughly in a high-speed mixer at a rate of $11,000 \mathrm{rpm}(\mathrm{Li}$ et al. 2016c). At last, certain concentrations of inhibitors were added to the basic WBDF. (2) The evaluation of inhibition performance of WBDF with inhibitors. For the WBDF with inhibitors, their rheological parameters including apparent viscosity (AV), plastic viscosity (PV), yield point (YP), yield point and plastic viscosity ratio (YP/PV), and gel strength, API filtrate volume after hot rolling $\left(120^{\circ} \mathrm{C}\right.$, $16 \mathrm{~h}$ ) were measured in light of the standard test recommended by API RP 13B-2 (2005). According to the method in Sect. 2.3.1, the hot rolling recovery of the drill cuttings in the WBDF with inhibitors was obtained.

\section{Results and discussion}

\subsection{Inhibition performance of $\mathrm{KCl}$ and PEG}

\subsubsection{Hot rolling recovery tests}

Hot rolling recovery tests were used to evaluate the swelling ability of the shale. An improved inhibitive capacity can be indicated by higher cuttings recovery (Khodja et al. 2010). In application, 3\%-10\% $\mathrm{KCl}$ and 5\%-7\% PEG (by weight) are commonly used (Hale and Blytas 1993; Reid et al. 2003; Smith and Balson 2004). After hot rolling at $120^{\circ} \mathrm{C}$ for $16 \mathrm{~h}$, the cutting recovery of the different systems was measured (Fig. 1). The hot rolling recovery of cuttings in the $\mathrm{KCl}$ solution was lower than that in the $\mathrm{PEG}+\mathrm{KCl}$ solution, as shown in Fig. 1a. With increasing the $\mathrm{KCl}$ concentration from 0 to

Table 1 Formulation of basic WBDF

\begin{tabular}{|c|c|c|}
\hline Composition & Dosage, wt $\%$ & Function \\
\hline Fresh water & 93.3 & Dispersion medium \\
\hline Bentonite & 4.0 & $\begin{array}{l}\text { Increase viscosity } \\
\text { and shear force }\end{array}$ \\
\hline $\mathrm{Na}_{2} \mathrm{CO}_{3}$ & 0.2 & Increase viscosity \\
\hline PAM & 0.5 & Increase viscosity \\
\hline CMC & 1.0 & Reduce filtration loss \\
\hline
\end{tabular}



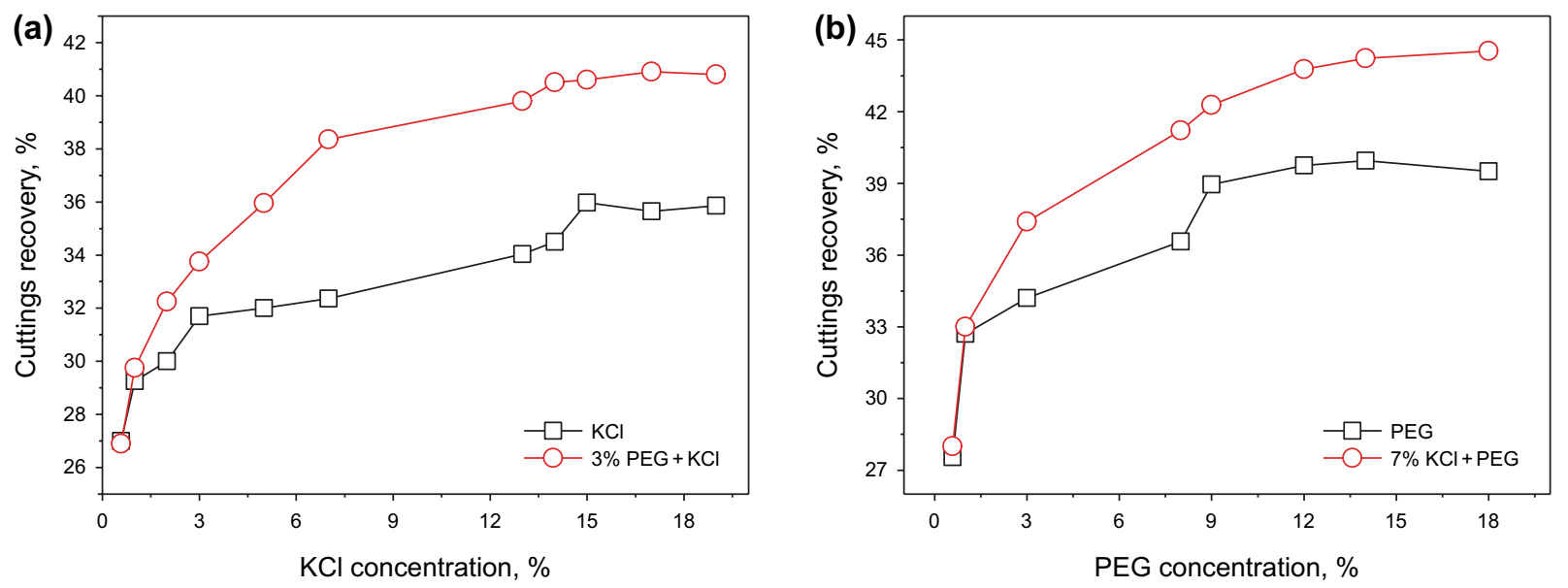

Fig. 1 Hot rolling recovery of cuttings in solutions containing different inhibitors

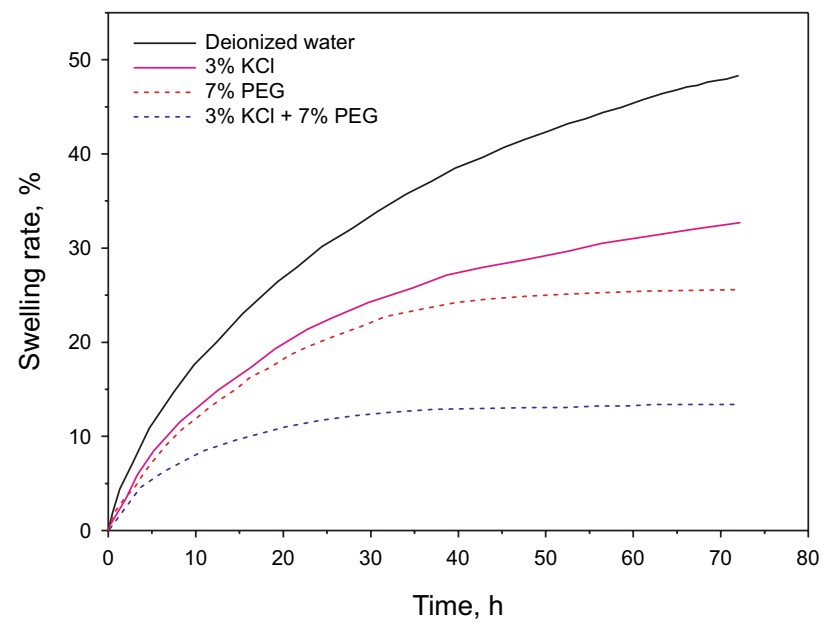

Fig. 2 Linear swell rate of the different inhibitive systems

$19 \%$, the hot rolling recovery of cuttings in the $\mathrm{KCl}$ solution increased from $27 \%$ to $35 \%$ and increased from $27 \%$ to $41 \%$ in the PEG+KCl solution. As shown in Fig. 1b, the hot rolling recovery of cuttings in the PEG solution was also lower than that in the PEG+KCl solution. With increasing the PEG concentrations from 0 to $18 \%$, the hot rolling recovery of cuttings in the PEG solution increased from $28 \%$ to $40 \%$ and increased from $28 \%$ to $45 \%$ in the $\mathrm{PEG}+\mathrm{KCl}$ solution. This shows that the order of inhibition capacity of the three systems is $\mathrm{PEG}+\mathrm{KCl}>\mathrm{PEG}>\mathrm{KCl}$.

\subsubsection{Linear swell tests}

Linear swell tests are widely used to evaluate shale expansibility (van Oort et al. 2016). The linear swell rates of the three different inhibition systems are shown in Fig. 2. Lower linear swell rate indicates an improved inhibition performance. From the data, both PEG and $\mathrm{KCl}$ have inhibitive capacity, which are lower than the inhibitive capacity of PEG+KCl. The order of linear swell rates was deionized water $>\mathrm{KCl}>\mathrm{PEG}>\mathrm{PEG}+\mathrm{KCl}$. Compared with the linear swell rate of deionized water, the linear swell rates of $\mathrm{KCl}$, PEG and PEG+KCl were reduced by $69 \%, 51 \%$ and $26 \%$, respectively, after $72 \mathrm{~h}$.

According to the results of hot rolling recovery test and linear swell test, it can be concluded that $\mathrm{PEG}+\mathrm{KCl}$ showed an improved inhibition performance than that of PEG or $\mathrm{KCl}$. PEG+KCl has synergistic inhibition effect.

\subsection{Analysis of the inhibitive mechanism}

\subsubsection{Fourier transform infrared spectroscopy}

In order to reveal the adsorption relationship between PEG and Na-Mt, FTIR spectrums of Na-Mt with different inhibitors were measured with Nicolet 6700 FTIR spectrometer, whose results are shown in Fig. 3. The absorption bands at 1000 and $1631 \mathrm{~cm}^{-1}$ were observed in three FTIR spectrums, corresponding to the $\mathrm{Si}-\mathrm{O}$ stretching vibration of tetrahedral sheets and $\mathrm{Si}-\mathrm{OH}$ bending vibration (Biasci et al. 1995). For Na-Mt/3\% KCl+7\% PEG and Na-Mt/7\% PEG, bands at 3450,1481 and $1220 \mathrm{~cm}^{-1}$ corresponded to $\mathrm{H}-\mathrm{O}$ stretching vibrations, $\mathrm{C}-\mathrm{H}$ bending vibrations and -O- stretching vibrations, respectively (Theng 1974). Bands at $2915 \mathrm{~cm}^{-1}$ and $2875 \mathrm{~cm}^{-1}$ were attributed to the $\mathrm{C}-\mathrm{H}$ stretching vibration. Therefore, $\mathrm{PEG}$ adsorbed onto the $\mathrm{Na}-\mathrm{Mt}$ with or without $\mathrm{KCl}$. It is proved that the adsorption of PEG is related to synergistic effect of PEG+KCl. 


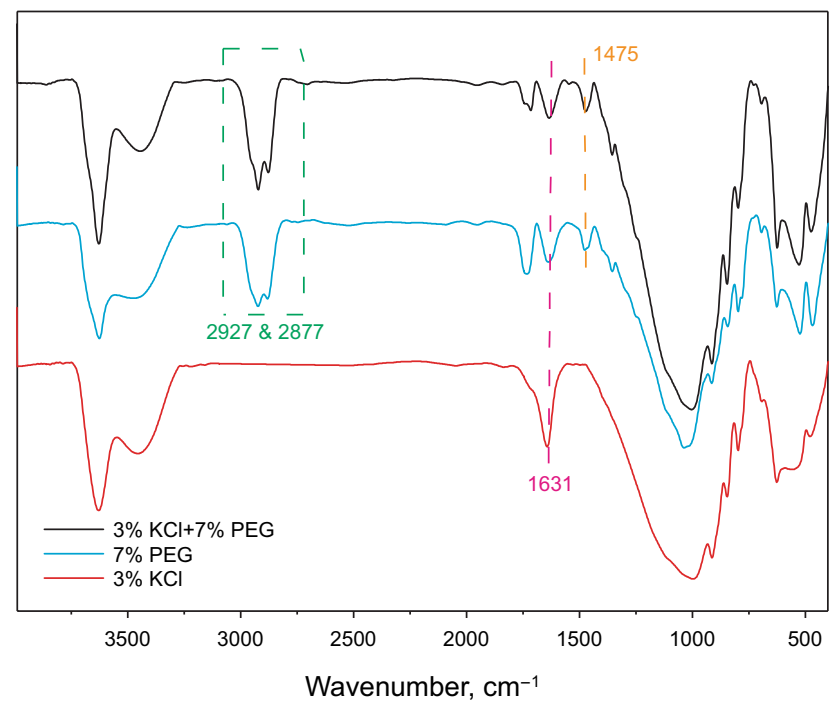

Fig. 3 FTIR spectrums of Na-Mt in the presence of different inhibitors

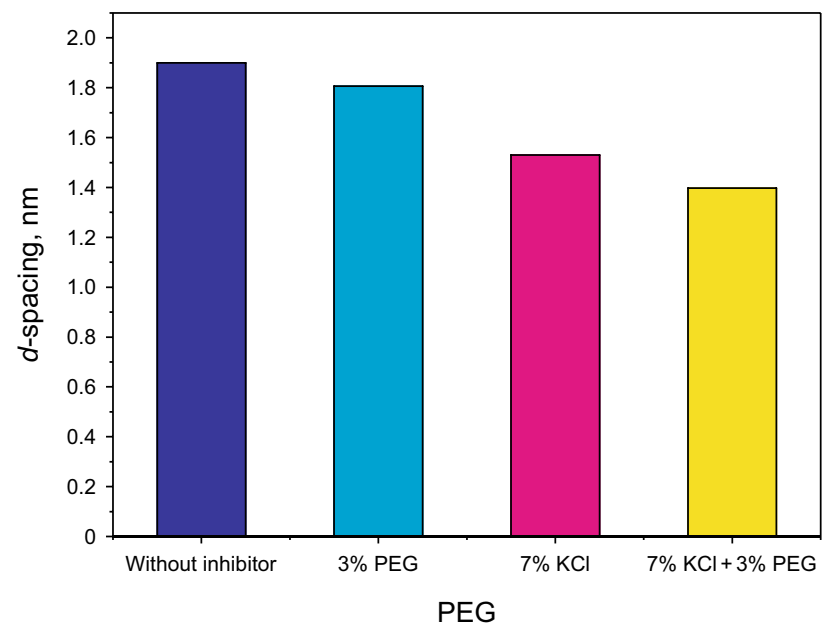

Fig. $4 d$-spacing of the wet Na-Mt with different inhibitors

\subsubsection{X-ray diffraction}

To study the effect of inhibitors on the structure of Na-Mt, the $d$-spacing of Na-Mt with different inhibitors was tested by XRD, as shown in Fig. 4. The $d$-spacing of Na-Mt with $3 \%$ PEG was $1.81 \mathrm{~nm}$. The $d$-spacing of Na-Mt with $7 \% \mathrm{KCl}$ was $1.53 \mathrm{~nm}$. The $d$-spacing of Na-Mt with 3\% PEG and 7\% $\mathrm{KCl}$ was $1.40 \mathrm{~nm}$. The three $d$-spacing values were lower than the $d$-spacing related to hydrated Na-Mt $(1.91 \mathrm{~nm})$ (Xie et al. 2017), which indicates that the three inhibition systems (KCl, PEG and PEG+KCl) can decrease $d$-spacing, repel water molecules of interlayer and inhibit hydration of Na-Mt. Therefore, the order of inhibition performance is as

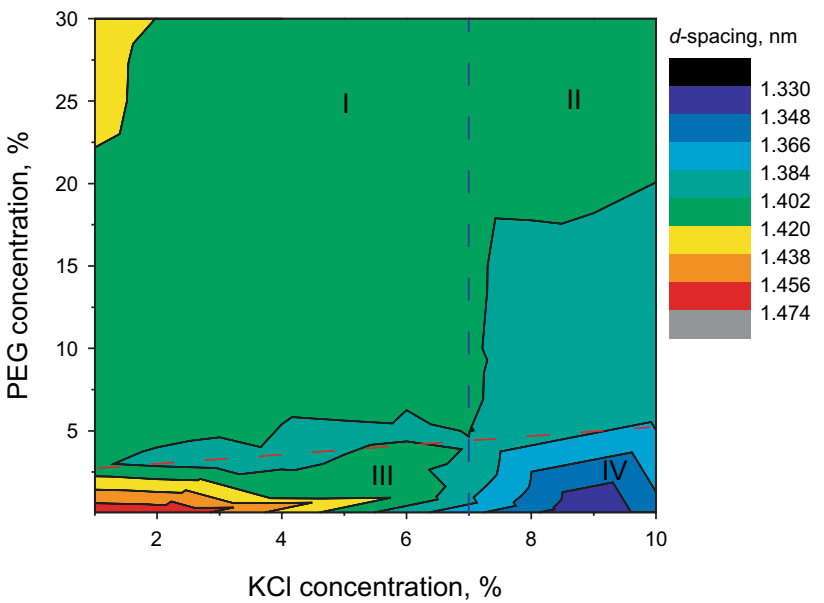

Fig. 5 Changes in $d$-spacing of wet Na-Mt according to $\mathrm{KCl}$ and PEG concentrations

follows: PEG+KCl $>\mathrm{KCl}>$ PEG. Moreover, the results of XRD also show the synergistic effect on the reduction in $d$-spacing.

When the mixed solution $(\mathrm{PEG}+\mathrm{KCl})$ was used, changes in $d$-spacing in the presence of each $\mathrm{KCl}$ and PEG concentration are shown in Fig. 5. Two obviously changes are observed. In terms of PEG dosage, Fig. 5 can be divided into two regions by red dash line (1.40 nm of $d$-spacing as the dividing line). In terms of $\mathrm{KCl}$ dosage, Fig. 5 can be divided into two regions by blue dash line ( $7 \%$ of $\mathrm{KCl}$ dosage as the dividing line). And the two dash lines divide Fig. 5 into four regions (I, II III, IV).

(1) Analysis of differences between $d$-spacing and $\mathrm{KCl}$ concentration relations with low PEG and high PEG concentration

When the PEG concentration was below the red dash line, the $d$-spacing of Na-Mt rapidly decreased from 1.47 to $1.33 \mathrm{~nm}$ with an increase in $\mathrm{KCl}$ concentration. When the PEG concentration was above the red dash line, the $d$-spacing of Na-Mt slowly decreased with an increase in $\mathrm{KCl}$ concentration. When the concentration of $\mathrm{KCl}$ increased, an increase in the number of $\mathrm{K}^{+}$ could strengthen the interaction between PEG and $\mathrm{K}^{+}$, which resulted in a decrease in $d$-spacing (Sun et al. 2005). The differences between the $d$-spacing and the $\mathrm{KCl}$ concentration relations with low PEG and high PEG concentration may be due to the filling conditions of PEG in the interlayer spacing of Na-Mt. When the PEG concentration was below the red dash line, the PEG molecules did not fill up the whole interlayer spacing of Na-Mt, as shown in Fig. 6a. There were some gaps in the spacing. Thus, the $d$-spacing could rapidly decrease by compressing the gaps when the concentra- 
(a)

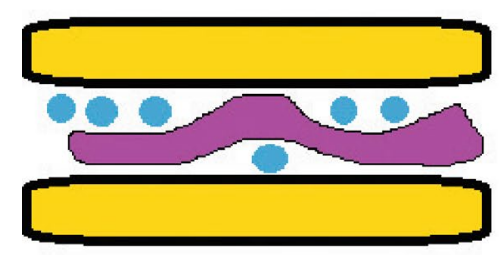

(b)

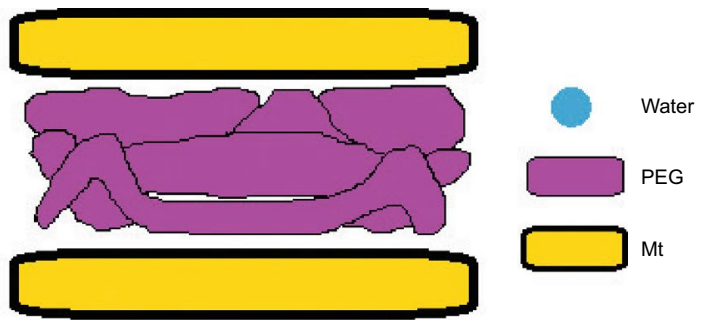

Fig. 6 Schematic of the PEG filling conditions. a PEG concentration below red dash line in Fig. 5; b PEG concentration above red dash line in Fig. 5

Table 2 The critical factors of $d$-spacing of Na-Mt with difference $\mathrm{KCl}$ and $\mathrm{PEG}$ concentrations

\begin{tabular}{ll}
\hline The region in Fig. 5 & Critical factors \\
\hline I & Accumulation height of PEG \\
II & Accumulation height of PEG \\
III & Hydration radius of $\mathrm{K}^{+}$ \\
IV & Accumulation height of PEG \\
\hline
\end{tabular}

tion of $\mathrm{KCl}$ increased. When the PEG concentration was above the red dash line, it can be considered that PEG filled up the whole interlayer spacing of $\mathrm{Na}-\mathrm{Mt}$, as shown in Fig. 6b. The $d$-spacing of Na-Mt slowly decreased with $\mathrm{KCl}$ concentration, because there were not compressible gaps in the spacing of interlayer of Na-Mt.

(2) Analysis of differences between $d$-spacing and PEG concentration relations with low $\mathrm{KCl}$ and high $\mathrm{KCl}$ concentration

When the $\mathrm{KCl}$ concentration was below $7 \%$, the $d$-spacing of Na-Mt initially decreased and then increased with an increase in PEG concentration. However, the $d$-spacing of Na-Mt showed an increased trend with increasing PEG concentration at the $\mathrm{KCl}$ concentration greater than $7 \%$. The main difference of above behavior is at PEG concentration below the red dash line of Fig. 5. The differences between the $d$-spacing and the PEG concentration with low $\mathrm{KCl}$ and high $\mathrm{KCl}$ concentrations may be due to their different critical factors (accumulation height of PEG and hydration radius of $\mathrm{K}^{+}$). When the $\mathrm{KCl}$ concentration was below $7 \%$, the critical factor was the hydration radius of $\mathrm{K}^{+}$. When the concentration of PEG increased, more water molecules bonded with $\mathrm{K}^{+}$were replaced by $\mathrm{PEG}$ molecules, which resulted in decreases in the hydration radius of $\mathrm{K}^{+}$and $d$-spacing of $\mathrm{Na}-\mathrm{Mt}$. When the $\mathrm{KCl}$ concentration was above $7 \%$, the $d$-spacing of $\mathrm{Na}-\mathrm{Mt}$ increased with increasing PEG concentration, because more PEG molecules accumulated in the interlayer of Na-Mt. More importantly, it can be concluded that the
Table 3 Mutual behavior of different regions in Fig. 5

\begin{tabular}{ll}
\hline Regions & Mutual behaviors \\
\hline I, II & $\begin{array}{c}d \text {-spacing slowly increases with an increase in } \mathrm{KCl} \text { con- } \\
\text { centration }\end{array}$ \\
III, IV $\quad \begin{array}{l}\text {-spacing rapidly increases with an increase in } \mathrm{KCl} \\
\text { concentration }\end{array}$ \\
I, III $\quad \begin{array}{l}\text {-spacing initially decreases and then increases with an } \\
\text { increase in PEG concentration }\end{array}$ \\
II, IV $\quad d$-spacing increases with an increase in PEG concentration
\end{tabular}

number of coordinated water molecules of coordination compound of PEG and $\mathrm{KCl}$ was significantly reduced at the $\mathrm{KCl}$ concentration above $7 \%$.

In summary, based on the results and analysis of Fig. 5, the change of $d$-spacing with changes of $\mathrm{KCl}$ and PEG concentrations can be concluded into two tables (Tables 2 and 3 ). Table 2 gives the critical factors of $d$-spacing of $\mathrm{Na}-\mathrm{Mt}$ with difference in $\mathrm{KCl}$ and PEG concentrations. Table 3 gives the mutual behavior of different regions in Fig. 5.

\subsection{KCl-PEG-Mt interaction mechanism by chemical characterization and SEM characterization}

In the above part, we discussed the influence of two inhibitors on Na-Mt structure at different concentrations by taking $d$-spacing as the index. However, the $d$-spacing is the result of multiple physical processes. In this section, these processes are studied further.

\subsubsection{Elemental analysis}

In order to reveal the interaction between $\mathrm{KCl}$ and $\mathrm{PEG}$, the carbon content of Na-Mt/inhibitor complexes was tested by elemental analysis. Because Na-Mt only has low levels of organic carbon, the carbon content of Na-Mt/inhibitor complexes shows the adsorption quantity of PEG on Na-Mt. The carbon content analysis of the Na-Mt with 3\% PEG 


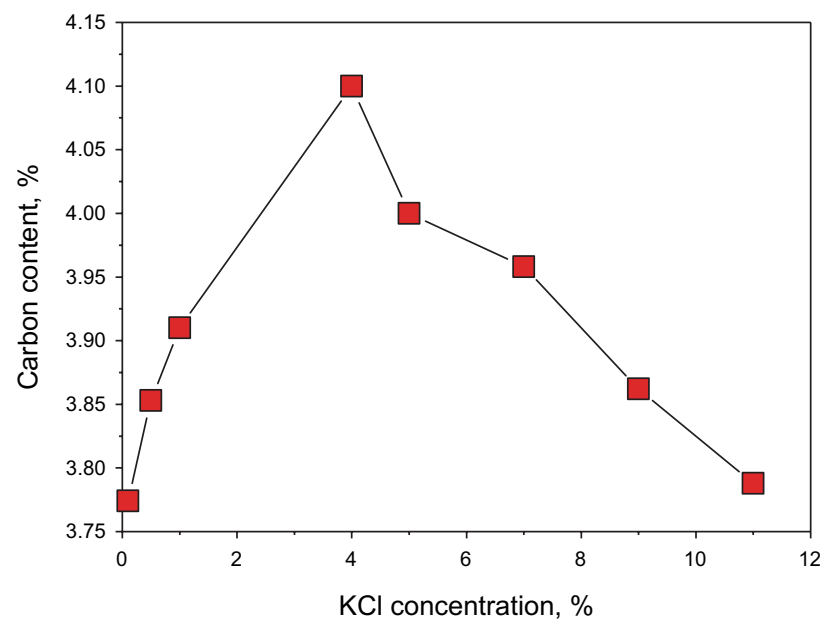

Fig. 7 Carbon content of Na-Mt/inhibitor complexes with different $\mathrm{KCl}$ concentrations and 3\% PEG

and different $\mathrm{KCl}$ concentrations are shown in Fig. 7. With increasing $\mathrm{KCl}$ concentration from $0.1 \%$ to $4 \%$, the adsorption quantity of PEG increased, implying that $\mathrm{KCl}$ promoted PEG adsorption at this concentration range. This promotion effect is attributed to the mutual attraction between $\mathrm{KCl}$ and PEG (Yanagida et al. 1977, 1978a, b). With increasing KCl concentration from $4 \%$ to $11 \%$, the adsorption quantity of PEG decreased, which indicates that $\mathrm{KCl}$ can inhibit the adsorption of PEG. This was likely due to the competitive adsorption relationship between $\mathrm{PEG}$ and $\mathrm{KCl}$ on the surface of Na-Mt. It can be concluded that the promotion effect was dominant when the $\mathrm{KCl}$ concentration was lower than $4 \%$, while the competitive adsorption was dominant when the $\mathrm{KCl}$ concentration was higher than $4 \%$.

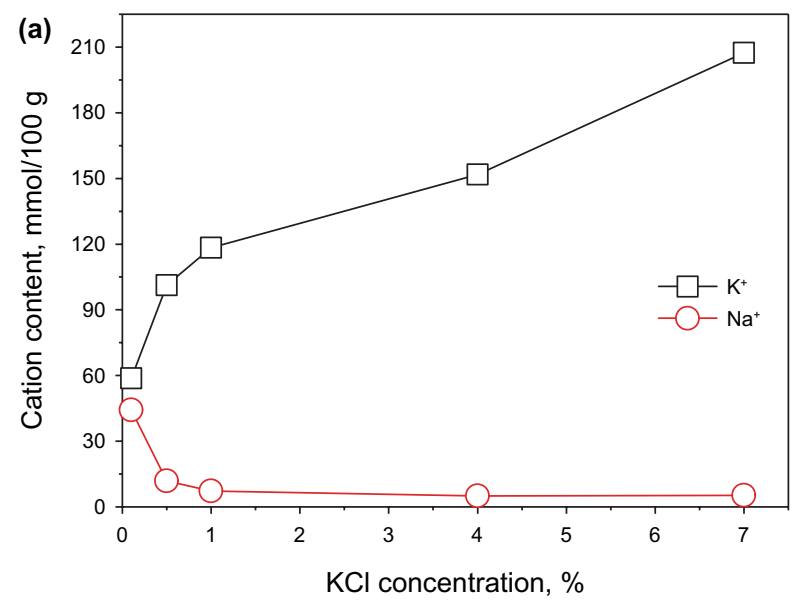

\subsubsection{Atomic absorption spectroscopy}

To study the adsorption quantity of $\mathrm{K}^{+}$and $\mathrm{Na}^{+}$, a series of Na-Mt with different concentrations of $\mathrm{KCl}$ and PEG were analyzed with an atomic absorption spectrophotometer. The adsorption capacity of Na-Mt with 3\% PEG and different concentrations of $\mathrm{KCl}$ are shown in Fig. 8a. With an increase in $\mathrm{KCl}$ concentration, the adsorption quantity of $\mathrm{Na}^{+}$rapidly decreased. The adsorption quantity of $\mathrm{K}^{+}$ adsorbed onto the clay surface increased with an increase in $\mathrm{KCl}$ concentration. The adsorption quantity of $\mathrm{K}^{+}$and $\mathrm{Na}^{+}$of Na-Mt with $7 \% \mathrm{KCl}$ and different concentrations of PEG are shown in Fig. 8b. With an increase in PEG concentration, the adsorption quantity of $\mathrm{Na}^{+}$remained unchanged, because the amount of $\mathrm{K}^{+}$is sufficient to displace all the exchangeable cations at the $\mathrm{KCl}$ concentration of $7 \%$. Additionally, the adsorption amount of $\mathrm{K}^{+}$ decreased as the PEG concentration increased from $0.5 \%$ to $5 \%$, and the adsorption amount remained constant after the PEG concentration was above $7 \%$. These phenomena can be attributed to the different types of adsorption of $\mathrm{K}^{+}$. On the surface of Na-Mt, there are three types of adsorption sites: oxygen atom of hexagonal site of silica, $\mathrm{H}_{\mathrm{Al}}$ and $\mathrm{T}_{\mathrm{Al}}$, which are defined in Fig. 9 (Ruankaew et al. 2020). The main adsorption force of $\mathrm{K}^{+}$is the isomorphic substitution in tetrahedral sheet and octahedral sheet ( $\mathrm{Li}$ et al. 2018). So, the adsorption strength of the oxygen atom of hexagonal site of silica is lower than those of $\mathrm{H}_{\mathrm{Al}}$ and $\mathrm{T}_{\mathrm{Al}}$. Based on the experimental results of atomic absorption spectroscopy, it can be considered that the adsorption sites of $\mathrm{H}_{\mathrm{Al}}$ and $\mathrm{T}_{\mathrm{Al}}$ are only occupied by $\mathrm{K}^{+}$, whose adsorption is not affected by PEG. The adsorption sites of the oxygen atom of hexagonal site of silica can be occupied by both $\mathrm{K}^{+}$and PEG. And the adsorption amounts of $\mathrm{K}^{+}$and PEG depend on their concentration ratio. Their

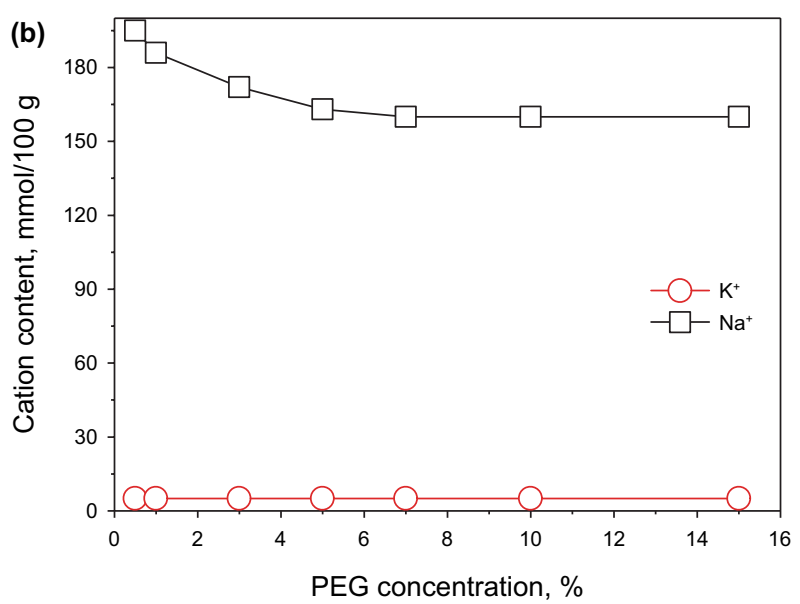

Fig. 8 Variations in cation content according to inhibitor concentrations: a different $\mathrm{KCl}$ concentrations and 3\% PEG; b different PEG concentrations and $7 \% \mathrm{KCl}$ 


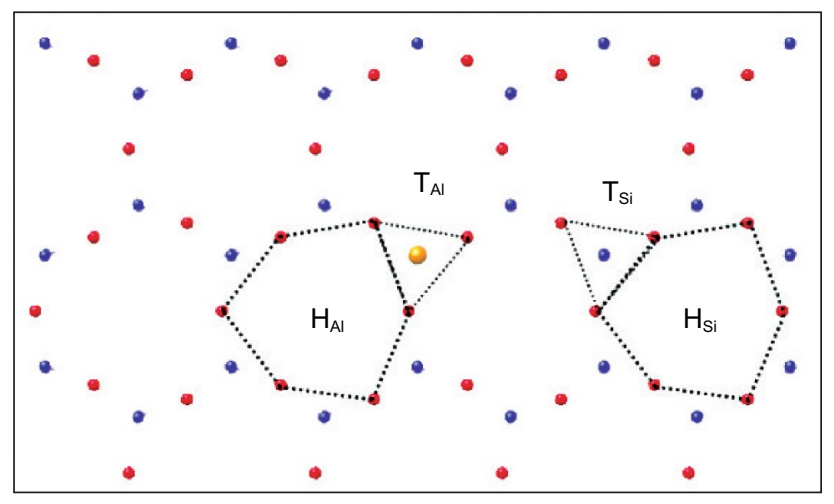

Fig. 9 A most top surface of Mt with the isomorphous replacement of silica by aluminum. Atomic legends were colored highlight as silica (light blue), oxygen (red), hydrogen (white) and aluminum (orange). Dotted triangles, $\mathrm{T}_{\mathrm{Si}}$ and $\mathrm{T}_{\mathrm{Al}}$, represent the triangular site of silica and aluminum, respectively. Dotted hexagons, $\mathrm{H}_{\mathrm{Si}}$ and $\mathrm{H}_{\mathrm{Al}}$, represent the hexagonal site next to the triangular site of silica and aluminum, respectively

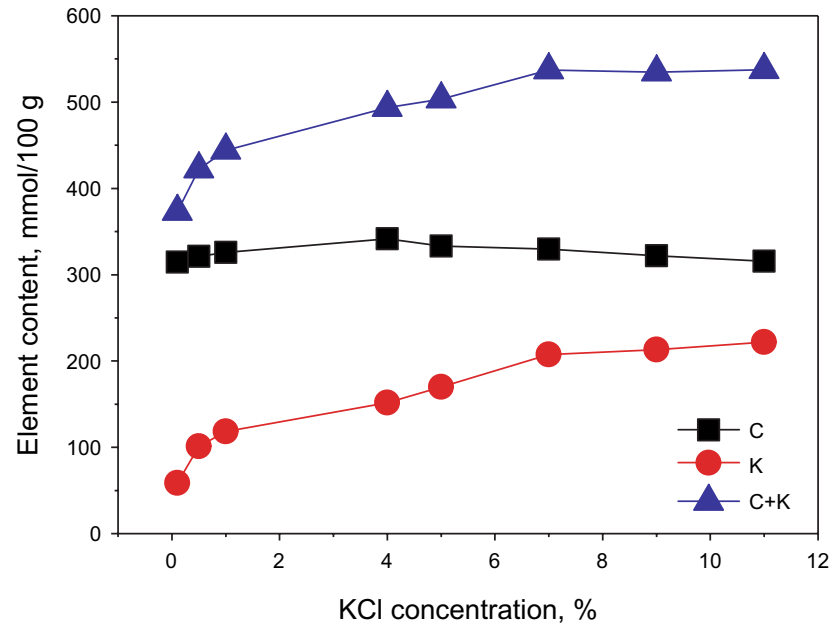

Fig. 10 Elemental contents with different $\mathrm{KCl}$ concentrations

competitive adsorption capacity increased when the PEG concentration increased from $0.5 \%$ to $5 \%$, which resulted in an increase in the adsorption amount of PEG. When the PEG concentration was above $7 \%$, all the sites of $\mathrm{H}_{\mathrm{Al}}$ and $\mathrm{T}_{\mathrm{Al}}$ were occupied by $\mathrm{K}^{+}$, and all the sites of the oxygen atom of hexagonal site of silica were occupied by PEG. Therefore, the adsorption amount of $\mathrm{K}^{+}$is not affected by PEG concentration.

By comprehensive analysis of the results of elemental analysis and atomic absorption spectrophotometry as shown in Fig. 10, the initial assessment of the optimal $\mathrm{KCl}$ concentrations can be performed. The PEG adsorption capacity reached its peak when the $\mathrm{KCl}$ concentration is $4 \%$. Nevertheless, as considering the adsorption of $\mathrm{K}^{+}$, the total adsorption reached its peak value when the $\mathrm{KCl}$ concentration is above $7 \%$. Considering the cost, the $\mathrm{KCl}$ concentration range of $6 \%-8 \%$ is the most suitable. When the total adsorption reached the peak, the synergistic effect was most likely to be exerted. Therefore, the estimated concentration range had a good effect.

\subsubsection{X-ray photoelectron spectroscopy}

In order to demonstrate the substitution of $\mathrm{Na}^{+}$by $\mathrm{K}^{+}$and the synergistic effects of $\mathrm{KCl}$ and $\mathrm{PEG}$, dry Na-Mt samples with different inhibitors were tested by XPS, as shown in Fig. 11. XPS can be used to investigate the surface composition of Na-Mt with different inhibitors (Jiang et al. 2016). The XPS spectra of Na $1 s$ of Na-Mt with different inhibitors are shown in Fig. 11a. Blank spectrum was tested with Na-Mt without inhibitors. Compared with the blank spectrum, the signal peak of $\mathrm{Na}-\mathrm{Mt}$ with $3 \% \mathrm{KCl}$ became weaker, which showed that $\mathrm{KCl}$ replaced $\mathrm{Na}^{+}$in $\mathrm{Na}-\mathrm{Mt}$. In addition, the signal peak of Na-Mt with 3\% $\mathrm{KCl}$ and $7 \%$ PEG was similar to that with $3 \% \mathrm{KCl}$. It suggests that PEG cannot influence the displacement of $\mathrm{Na}^{+}$ by $\mathrm{KCl}$.

In the XPS spectra of K $2 p$ of Na-Mt with different inhibitors (Fig. 11b), the blank spectrum was obtained without inhibitor and showed no $\mathrm{K} 2 p$ signal, which indicates that $\mathrm{Na}-\mathrm{Mt}$ does not contain $\mathrm{K}^{+}$. After addition of $3 \% \mathrm{KCl}$, the signal peak became stronger. Then, after further addition of $7 \%$ PEG, the signal peak became weaker, which possibly resulted from competitive adsorption between $\mathrm{KCl}$ and PEG on Na-Mt. This was confirmed through the elemental analysis in Sect. 3.3.1. Moreover, the $\mathrm{Na}-\mathrm{Mt} / \mathrm{KCl}$ binding energy of $\mathrm{K} 2 p$ increased from 295.8, 293.1 to 295.9, 293.2 eV after PEG addition, implying that PEG undergoes binding with $\mathrm{K}^{+}$. This was also demonstrated through the elemental analysis in Sect. 3.3.1.

\subsubsection{Scanning electron microscopy}

SEM was used to observe the morphology of wet Na-Mt with different inhibitor systems. The morphology of pure Na-Mt was a layered structure, as shown in Fig. 12a. Following the addition of $3 \%$ PEG, the morphology of Na-Mt with PEG was still layered structure in Fig. 12b, which was similar to that of pure Na-Mt. After the addition of $7 \%$ $\mathrm{KCl}$, some of the Na-Mt particles showed spherical structures, as illustrated in Fig. 12c. When 3\% PEG and 7\% KCl were used together as a synergistic inhibitor, the majority of Na-Mt particles exhibited spherical structures, as shown in Fig. 12d. Inhibitors usually have strong adsorption 

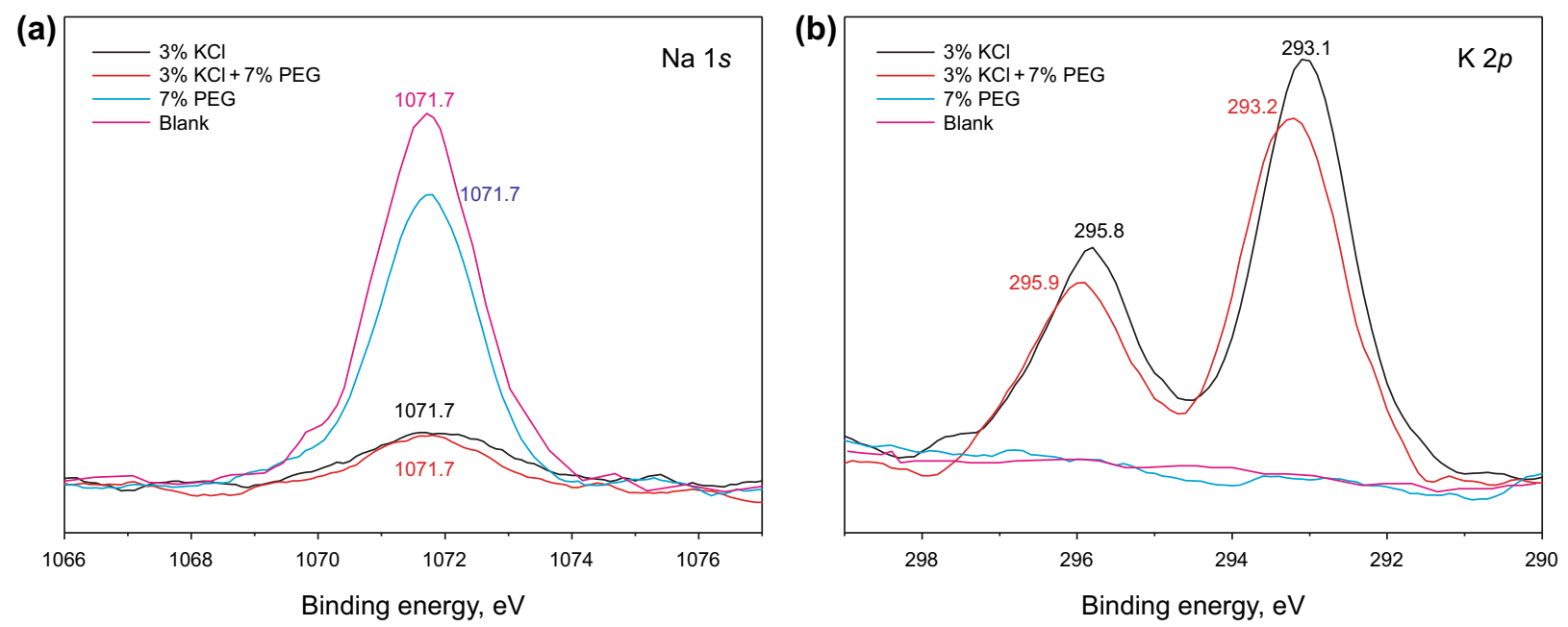

Fig. 11 XPS patterns of Na-Mt with the different inhibitors: a Na $1 s$ pattern; b K $2 p$ pattern
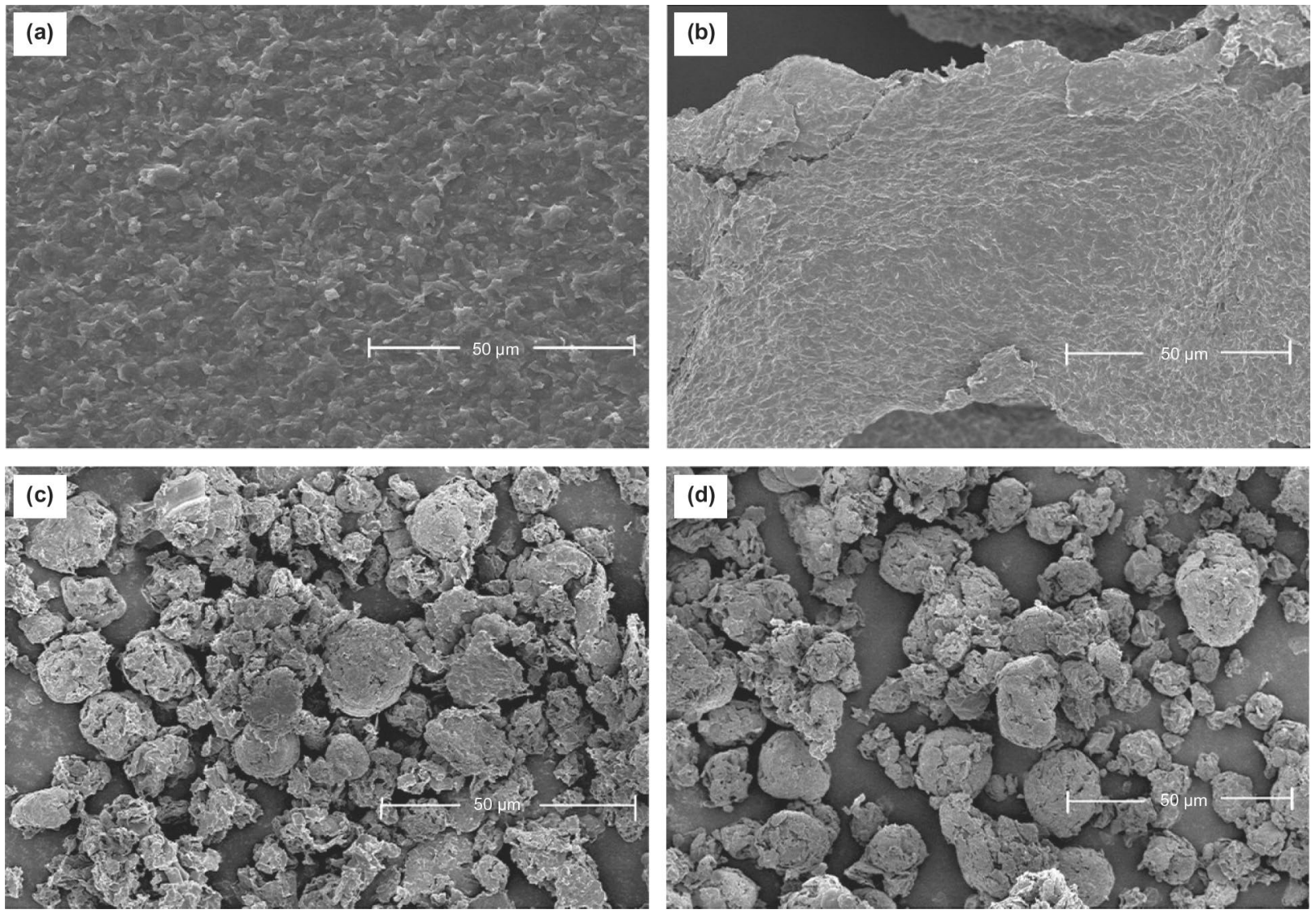

Fig. 12 SEM images of wet Na-Mt/inhibitors: a Na-Mt; b Na-Mt/PEG; $\mathbf{c}$ wet $\mathrm{Na}-\mathrm{Mt} / \mathrm{KCl}$; $\mathbf{d}$ wet $\mathrm{Na}-\mathrm{Mt} / \mathrm{PEG}+\mathrm{KCl}$

capacity, which allows them to replace water molecules and decrease $d$-spacing of Na-Mt. The strong adsorption capacity causes Na-Mt to aggregate, which results in the spherical structure of Na-Mt (Xie et al. 2017). Therefore, by comparing the morphology of wet Na-Mt with different inhibitor systems, the order of inhibition performance was determined to be $\mathrm{PEG}+\mathrm{KCl}>\mathrm{KCl}>$ PEG. 


\subsection{Optimization of PEG and $\mathrm{KCl}$ concentrations}

The optimization of PEG and $\mathrm{KCl}$ concentrations was as follows: (1) XRD was used to identify the boundary of changing trend in $d$-spacing with an increase in PEG concentration. When concentration ranges of $\mathrm{PEG}$ and $\mathrm{KCl}$ were on the boundary (the red dash line in Fig. 5), the interlayer spacing of Na-Mt was filled up by PEG. Hence, the optimal concentration of PEG was in this range. (2) XRD was also used to identify the boundary of changing trend in $d$-spacing with an increase in $\mathrm{KCl}$ concentration. At the $\mathrm{KCl}$ concentration above the boundary, the number of coordinated water molecules of the PEG-KCl coordination compound was significantly reduced. In consideration of cost, the optimal concentration of $\mathrm{KCl}$ should be near the boundary (the blue dash line in Fig. 5). (3) The intersection of the above two boundaries represents the optimal $\mathrm{KCl}$ and $\mathrm{PEG}$ concentrations.

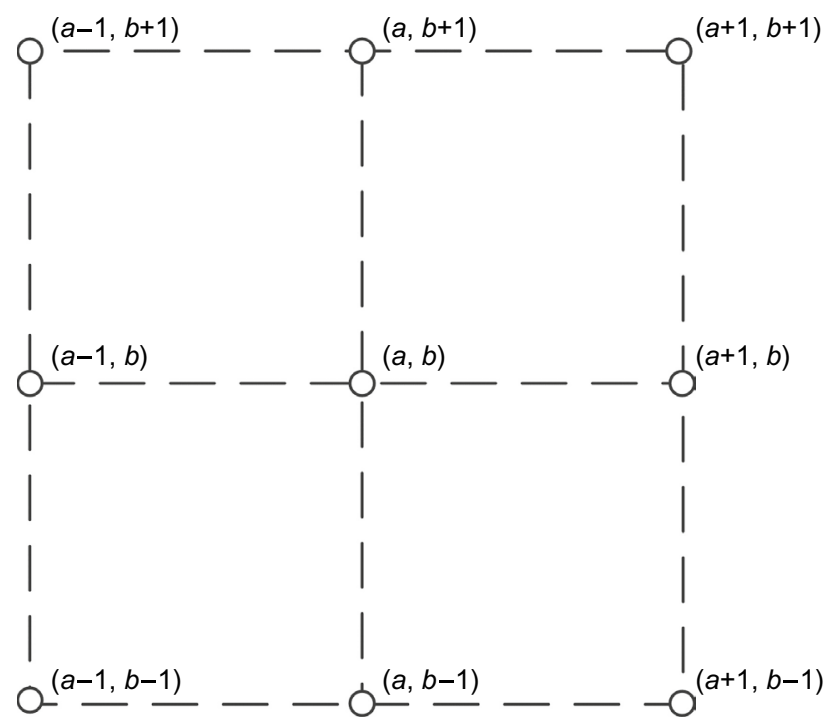

a: PEG concentration, \%; $b$ : $\mathrm{KCl}$ concentration, \%

Fig. 13 Schematic diagram of concentration optimization
The optimal $\mathrm{KCl}$ and PEG concentrations should be near the intersection of the above two boundaries. Then, several concentrations were selected, as shown in Fig. 13. The optimal $\mathrm{KCl}$ and $\mathrm{PEG}$ concentrations were chosen from the different concentrations by the shale hot rolling recovery test.

For the Na-Mt sample studied in this work, the optimal concentrations of PEG and $\mathrm{KCl}$ were obtained as $7 \% \mathrm{KCl}$ and 5\% PEG. Then, the optimization of PEG and $\mathrm{KCl}$ concentrations was verified by a series of tests on Na-Mt. A set of water-based drilling fluids with different concentrations of $\mathrm{KCl}$ and PEG was designed. The corresponding basic rheological properties and API filtrate volumes are given in Table 4. The rheological properties and filtrate properties of the water-based drilling fluids are acceptable according to API RP 13B-2 (2005).

The shale hot rolling recovery results of water-based drilling fluids with different inhibitors are shown in Fig. 14. $\mathrm{KCl}$ and PEG improved the cutting recovery of the drilling fluids, indicating that both $\mathrm{KCl}$ and $\mathrm{PEG}$ can improve inhibition properties of water-based drilling fluids. The synergistic inhibitive effects of $\mathrm{KCl}$ and PEG were obvious, which resulted in higher cutting recovery. Moreover, the higher the concentration, the higher the cutting recovery. When $14 \% \mathrm{KCl}$ and 5\% PEG were used together as synergistic inhibitors (Fig. 14h), both the rheological properties and filtrate properties of the drilling fluid were unacceptable for engineering practice. Thus, for the $\mathrm{Na}-\mathrm{Mt}$ studied in this paper, $7 \% \mathrm{KCl}$ and $5 \%$ PEG were deemed to be the optimal concentrations.

\section{Conclusions}

The synergistic inhibition performance of PEG and $\mathrm{KCl}$ was evaluated through hot rolling recovery tests and linear swell tests on shale cuttings. For the inhibition of $\mathrm{Na}-\mathrm{Mt}$ hydration, the synergistic effect of $\mathrm{KCl}$ and $\mathrm{PEG}$

Table 4 Rheological properties and API filtrate volumes of drilling fluids with different inhibitors after hot rolling $\left(120^{\circ} \mathrm{C}, 16 \mathrm{~h}\right)$

\begin{tabular}{|c|c|c|c|c|c|c|c|}
\hline Sample No. & Inhibitors & $\mathrm{AV}, \mathrm{mPa} \mathrm{s}$ & $\mathrm{PV}, \mathrm{mPa} \mathrm{s}$ & $\mathrm{YP}, \mathrm{Pa}$ & $\begin{array}{l}\mathrm{YP} / \mathrm{PV}, \mathrm{Pa} / \\
(\mathrm{mP} \mathrm{s})\end{array}$ & $\begin{array}{l}\text { Gel strength } \\
(10 \mathrm{~s} / 10 \mathrm{~min}), \mathrm{Pa}\end{array}$ & $\begin{array}{l}\text { Filtrate } \\
\text { volume, } \\
\mathrm{cm}^{3}\end{array}$ \\
\hline a & Blank sample & 27.0 & 24.0 & 6.0 & 0.25 & $4.0 / 4.5$ & 11.4 \\
\hline $\mathrm{b}$ & $7 \% \mathrm{KCl}$ & 19.0 & 14.0 & 8.0 & 0.57 & $3.5 / 4.0$ & 12.6 \\
\hline $\mathrm{c}$ & $5 \% \mathrm{PEG}$ & 27.0 & 23.0 & 7.0 & 0.30 & $3.0 / 4.0$ & 8.4 \\
\hline $\mathrm{d}$ & $7 \% \mathrm{KCl}+1 \% \mathrm{PEG}$ & 24.0 & 20.0 & 7.0 & 0.35 & $3.0 / 4.0$ & 10.6 \\
\hline $\mathrm{e}$ & $1 \% \mathrm{KCl}+5 \% \mathrm{PEG}$ & 26.5 & 22.0 & 7.5 & 0.34 & $3.0 / 3.5$ & 7.8 \\
\hline $\mathrm{f}$ & $3.5 \% \mathrm{KCl}+2.5 \% \mathrm{PEG}$ & 28.0 & 24.0 & 8.0 & 0.35 & $3.5 / 4.0$ & 8.2 \\
\hline $\mathrm{g}$ & $7 \% \mathrm{KCl}+5 \mathrm{wt} \% \mathrm{PEG}$ & 25.5 & 20.0 & 8.5 & 0.43 & $3.0 / 3.5$ & 9.9 \\
\hline $\mathrm{h}$ & $14 \% \mathrm{KCl}+10 \% \mathrm{PEG}$ & 16.0 & 11.0 & 9.0 & 0.73 & $2.5 / 3.0$ & 14.3 \\
\hline
\end{tabular}




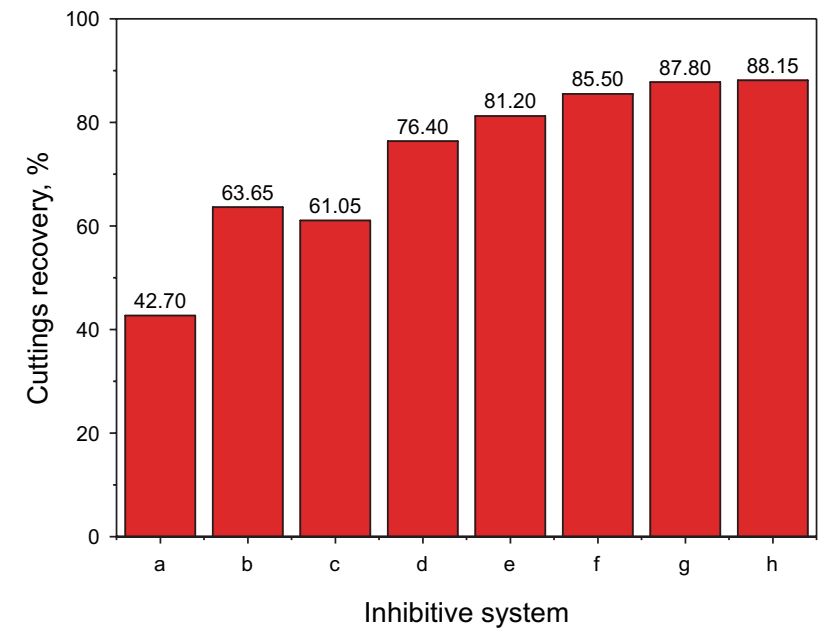

Fig. 14 Cutting recovery of different inhibitors: a blank sample; b 7\% $\mathrm{KCl}$; $5 \% \mathrm{PEG}$; d $7 \% \mathrm{KCl}+1 \% \mathrm{PEG}$; e $1 \% \mathrm{KCl}+5 \% \mathrm{PEG} ; \mathbf{f} 3.5 \%$ $\mathrm{KCl}+2.5 \%$ PEG; $\mathbf{g} 7 \% \mathrm{KCl}+5 \%$ PEG; $\mathbf{h} 14 \% \mathrm{KCl}+10 \%$ PEG

on inhibition ability was demonstrated by experimental results. A plausible mechanism including several processes was proposed to explain the experimental results. When KCl-PEG was applied as a synergistic inhibitor in water-based drilling fluids, a method for optimizing PEG and $\mathrm{KCl}$ concentrations was proposed. Several specific conclusions were drawn from the results as follows:

(1) According to PEG and $\mathrm{KCl}$ concentrations, the $d$-spacing of Na-Mt can be divided into four zones. These four zones correspond to different types of KCl-PEG-Mtwater interactions, respectively.

(2) The different processes, including competitive adsorption between $\mathrm{KCl}$ and PEG, the formation of PEG and $\mathrm{KCl}$ complex, and the filling conditions of PEG molecules with different concentrations in Na-Mt, control the roles played by different materials in Na-Mt swelling.

(3) The proposed optimization method is verified by the results of shale cutting recovery test for formulated water-based drilling fluids containing KCl-PEG inhibitor. This method can help to quickly determine the optimal concentrations of PEG and $\mathrm{KCl}$, which provides important information for drilling fluid design.

(4) For the studied Na-Mt, the optimized $\mathrm{KCl}$ and PEG concentrations are $5 \%$ and $7 \%$, respectively.

Acknowledgements This work was financially supported by the Natural Science Foundation of China (51974270), Innovation Union of China National Petroleum Corporation and Southwest Petroleum University (2020CX040102, 2020CX040201) and Open Fund (PLN201814) of the State Key Laboratory of Oil and Gas Reservoir Geology and Exploitation (Southwest Petroleum University).
Open Access This article is licensed under a Creative Commons Attribution 4.0 International License, which permits use, sharing, adaptation, distribution and reproduction in any medium or format, as long as you give appropriate credit to the original author(s) and the source, provide a link to the Creative Commons licence, and indicate if changes were made. The images or other third party material in this article are included in the article's Creative Commons licence, unless indicated otherwise in a credit line to the material. If material is not included in the article's Creative Commons licence and your intended use is not permitted by statutory regulation or exceeds the permitted use, you will need to obtain permission directly from the copyright holder. To view a copy of this licence, visit http://creativecommons.org/licenses/by/4.0/.

\section{References}

Al-Bazali TM. The consequences of using concentrated salt solutions for mitigating wellbore instability in shales. J Pet Sci Eng. 2011;80(1):94-101.

API. API RP 13B-2, recommended practice for field testing of oilbased drilling fluids. 4th edn. Washington, DC; 2005.

Baohua Y, Chuanliang Y, Qiang T, Jingen D, Shen G. Wellbore stability in high temperature and highly-depleted reservoir. Electronic J Geotech Eng. 2013;18:909-22.

Biasci L, Aglietto M, Ruggeri G. Functionalization of montmorillonite by acrylamide polymers containing side-chain ammonium cations. Polym Adv Technol. 1995;6(10):662-70. https://doi.org/10.1002/ pat.1995.220061004.

Bland R. Water-based glycol systems acceptable substitute for oil-based muds. Oil Gas J. 1992;90(26):5. https://doi.org/10.1016/01489062(93)90497-2.

Bland R, Smith GL, Eagark P, et al. Low salinity polyglycol waterbased drilling fluids as alternatives to oil-based muds. SPE/ IADC Asia Pacific Drill Technol Soc Pet Eng. 1996. https://doi. org/10.2118/29378-MS.

Bol GM, Wong SW, Davidson CJ, et al. Borehole stability in shales. SPE Drill Complet. 1994;9(02):87-94. https://doi. org/10.2118/24975-PA.

Boulet P, Covency PV, Stackhouse S. Simulation of hydrated $\mathrm{Li}^{+}{ }_{-}$, $\mathrm{Na}^{+}$-, and $\mathrm{K}^{+}$-montmorillonite/polymer nanocomposites using large scale molecular dynamics. Chem Phys Lett. 2004. https:// doi.org/10.2118/24975-PA.

Brady ME, Craster B, Getliff JM, Reid PI. Highly inhibitive, low-salinity glycol water-base drilling fluid for shale drilling in environmentally sensitive locations. In: SPE International Conference on Health, Safety, and Environment in Oil and Gas Exploration and Production, 7-10 June, Caracas, Venezuela. Society of Petroleum Engineers. 1998. Doi: https://doi.org/10.2118/46618-MS.

Cai L, Miao X, Li Y, Liu G, Jin J. Analysis of Wellbore Collapse in Continental Strata in Northeastern Sichuan Basin. Petroleum Drilling Techniques. 2008;36(6):39-43.

Cannon GE. Drilling fluid for combating heaving shale. US 219132 (1940).

Chaudhary D, Liu H. Ultrasonic treatment and synthesis of sugar alcohol modified $\mathrm{Na}^{+}$-montmorillonite clay. Ultrason Sonochem. 2013;20(1):63-8. https://doi.org/10.1016/j.ultsonch.2012.08.003.

Cook JM, Goldsmith G, Geehan TM, et al. Mud/shale interaction: model wellbore studies using X-ray tomography. In: SPE/IADC Drilling Conference. Society of Petroleum Engineers. 1993. https://doi.org/https://doi.org/10.2118/25729-MS.

Dzialowski A, Hale A, Mahajan S. Lubricity and wear of shale: effects of drilling fluids and mechanical parameters. In: SPE/IADC Drilling Conference. Society of Petroleum Engineers. 1993. https://doi. org/https://doi.org/10.2118/25730-MS. 
Guo J, Yan J, Fan W. Applications of strongly inhibitive silicate-based drilling fluids in troublesome shale formations in Sudan. J Petrol Sci Eng. 2006;50(3):195-203. https://doi.org/10.1016/j.petro 1.2005.12.006

Hale AH, Blytas GC. Alcohol-in-oil drilling fluid system comprising polycyclic polyetherpolyol. US Patent 5198416 (1993).

Isinak A, Smith V, Alessandro FD, et al. Application of a complex polyol drilling fluid in Albania. Oil Gas Eur Magaz. 2005;31(3):124.

Jiang GC, Qi YR, An YX, et al. Polyethyleneimine as shale inhibitor in drilling fluid. Appl Clay Sci. 2016. https://doi.org/10.1016/j. clay.2016.04.013.

Khodja M, Canselier PJ, Bergaya F, Fourar K, Khodja M, Cohaut N, Benmounah A. Shale problems and water-based drilling fluid optimization in the Hassi Messaoud Algerian oil field. Appl Clay Sci. 2010;49:383-93. https://doi.org/10.1016/j.clay.2010.06.008.

Lee DH, Kim HS, Yoon KB, et al. Polyethylene/MMT nanocomposites prepared by in situ polymerization using supported catalyst systems. Sci Technol Adv Mater. 2005;6(5):457-62. https://doi. org/10.1016/j.stam.2005.04.004.

Li W, Zhao X, Li Y, Ji Y, Peng H, Liu L, Yang Q. Laboratory investigations on the effects of surfactants on rate of penetration in rotary diamond drilling. J Pet Sci Eng. 2015;134:114-22. https://doi. org/10.1016/j.petrol.2015.07.027.

Li W, Zhao X, Ji Y, et al. Investigation of biodiesel-based drilling fluid, Part 2: formulation design, rheological study, and laboratory evaluation. SPE J. 2016b;21(05):1767-81. https://doi. org/10.2118/180926-PA.

Li W, Zhao X, Ji Y, et al. Investigation of biodiesel-based drilling fluid, part 1: biodiesel evaluation, invert-emulsion properties, and development of a novel emulsifier package. SPE J. 2016a;21(05):175566. https://doi.org/10.2118/180918-PA.

Li W, Zhao X, Ji Y, et al. An investigation on environmentally friendly biodiesel-based invert emulsion drilling fluid. J Pet Explor Prod Technol. 2016c;6(3):505-17. https://doi.org/10.1007/s1320 2-015-0205-7.

Li W, Liu J, Zhao X, Zhang J, Jiang J, He T, Liu L, Shen P, Zhang M. Novel modified rectorite provides reliable rheology and suspendability for biodiesel based drilling fluid. In: SPE/IADC Middle East Drilling Technology Conference and Exhibition, Abu Dhabi, UAE, 29-31 January, 2018. https://doi.org/https://doi. org/10.2118/189310-MS.

Li W, Liu J, Zhao X, Jiang J, Peng H, Zhang M, He T, Liu G, Shen P. Development and screening of additives for biodiesel based drilling fluids: principles, strategies and experience. In: SPE International Conference on Oilfield Chemistry, Galveston, Texas, USA, 8-9 April, 2019. https://doi.org/https://doi.org/10.2118/19359 7-MS.

Li W, Liu J, Zeng J, et al. A fully coupled multidomain and multiphysics model for evaluation of shale gas extraction. Fuel. 2020;15(278):118214. https://doi.org/10.1016/j.fuel.2020.118214.

Liu D, Xue B, Li J, Zhang Y, Liang Z, Cheng Z, et al. Research and Application of Heavy Mud Technology in Strong Mud-making Formations. Drill Fluid Complet Fluid. 2006;23(5):4-7.

Mody FK, Hale AH. Borehole-stability model to couple the mechanics and chemistry of drilling-fluid/shale interactions. J Pet Technol. 1993. https://doi.org/10.2118/25728-PA.

Qian X, Zhang J. Exploration and development technology of shale oil and gas in the world: progress, impact, and implication. IOP Conf Ser Earth Environ ENCE. 2020;526:012131.

Raza Khan MS, Pratap V, Sharma KC, Anilkumar BS, Gupta AK. Polyol drilling fluid: a novel solution to curb recurring drilling and completion problems in mature Sobhasan Field, Mehsana Asset, ONGC, India. In: SPE/IADC Indian Drilling Technology Conference and Exhibition, 16-18 October, Mumbai, India. Society of Petroleum Engineers. 2006. https://doi.org/10.2118/102040-MS.

Reid PI, Craster B, Crawshaw JP, et al. Drilling fluid. US Patent 6544933 (2003).

Ruankaew N, Kristinawati A, Yoshida N, Phongphanphanee S. A 3D-RISM study of water and potassium ion adsorption in Montmorillonite nanoclay. IOP Conf Ser Mater Sci Eng. 2020;773:012060.

Sartori R, Sepulveda L, Quina F, et al. Binding of electrolytes to poly (ethylene oxide) in aqueous solutions. Macromolecules. 1990;23(17):3878-81. https://doi.org/10.1021/ma00219a002.

Smith CK, Balson TG. Shale-stabilizing additives. US Patent 6706667 (2004).

Steiger R, Leung PK. Quantitative determination of the mechanical properties of shales. SPE Drill Eng. 1992;7(3):181-5. https://doi. org/10.2118/18024-PA.

Sun MB, Hou WG, Sun DJ, Dai XN. Interaction mechanism study on poly(ethylene oxide)-clay-alkali metal ion intercalation composites. Acta Chim Sinica. 2005;63(7):562-6.

Tasaki K. Poly (oxyethylene)-cation interactions in aqueous solution: a molecular dynamics study. Comput Theor Polym Sci. 1999;9(34):271-84. https://doi.org/10.1016/S1089-3156(99)00015-X

Theng BKG. The chemistry of clay-organic reactions. Chem Clay-Org React. 1974. https://doi.org/10.2136/sssaj1975.036159950039000 20002x.

Twynam AJ, Caldwell PA, Meads K. Glycol-enhanced water-based muds: case history to demonstrate improved drilling efficiency in tectonically stressed shales. In: SPE/IADC Drilling Conference. Society of Petroleum Engineers. 1994. doi: https://doi. org/10.2118/27451-MS.

van Oort E. On the physical and chemical stability of shales. J Petrol Sci Eng. 2003;38(3):213-35. https://doi.org/10.1016/S0920 $-4105(03) 00034-2$.

van Oort E, Hoxha BB, Hale A, et al. How to test fluids for shale compatibility. In: The AADE Fluids Technical Conference and Exhibition. American Association of Drilling Engineers, Houston, USA. 2016;1-9.

Wang Y, Meng Y, Li G, Li Y. Factor analysis of pressure used in managed pressure drilling on injected gas. Oil Drilling \& Production Technology. 2009;31(1):31-4.

Xie G, Luo P, Deng M, et al. Intercalation behavior of branched polyethyleneimine into sodium bentonite and its effect on rheological properties. Appl Clay Sci. 2017;141:95-103. https://doi. org/10.1016/j.clay.2017.02.018.

Yanagida S, Takahashi K, Okahara M. Metal-ion complexation of noncyclic poly (oxyethylene) derivatives. I. Solvent extraction of alkali and alkaline earth metal thiocyanates and iodides. Bull Chem Soc Jpn. 1977;50(6):1386-90. https://doi.org/10.1246/ bcsj.50.1386.

Yanagida S, Takahashi K, Okahara M. Metal-ion complexation of noncyclic poly (oxyethylene) derivatives. II. PMR studies of the complexation with alkali and alkaline-earth metal cations. Bull Chem Soc Jpn. 1978;51(5):1294-9. https://doi.org/10.1246/ bcsj.51.1294.

Yanagida S, Takahashi K, Okahara M. Metal-ion complexation of noncyclic poly (oxyethylene) derivatives. Complexation in aprotic solvent and isolation of their solid complexes. Bull Chem Soc Jpn. 1978;51(11):3111-20. https://doi.org/10.1246/bcsj.51.3111. 